\title{
VIDA EM POTÊNCIA: NIETZSCHE E AGAMBEN SOB A ÓTICA DE ASSMANN E BAZZANELLA
}

\author{
Alexandra Filomena Espindola ${ }^{1}$
}

Resenha de: BAZZANELLA, Sandro Luiz; ASSMANN, Selvino José. A vida como potência

a partir de Nietzsche e Agamben. São Paulo: LiberArs, 2013.

Selvino José Assmann é doutor em filosofia, professor da Universidade Federal de Santa Catarina (UFSC) e tradutor de Giorgio Agamben. Também filósofo, Sandro Luiz Bazzanella é doutor em Ciências Humanas e professor da Universidade do Contestado (UnC). Juntos escrevem o livro A vida como potência a partir de Nietzsche e Agamben, publicado em 2013. Eles se dedicam a explorar a urgência de se discutir sobre a vida. Para isso, buscam como Agamben lida com o tema vida, contando inicialmente com o conceito nietzschiano de potência. Essa "conversa" entre Agamben e Nietzsche, mediada criticamente por Assmann e Bazzanella nos deixa ver, já no prefácio, escrito por Márcia Tiburi, que a palavra vida é geralmente utilizada sem gravidade e sem critério, como se falasse por si e significasse um universo indiscriminado de seres sem relação com a história. O que Assmann e Bazzanella vão nos mostrar é o contrário desse pensamento generalizante ao proporem olharmos para a história e entendermos qual vida está em pauta em momentos e pensadores específicos.

O livro A vida como potência a partir de Nietzsche e Agamben está dividido em três grandes capítulos, em que os autores abordam já de início a vida como ponto de inflexão entre esses dois pensadores; depois colocam em pauta os questionamentos de Nietzsche a Agamben sobre a história e o tempo; e por último discutem as formas de vida na contemporaneidade na concepção da grande política e da política que vem.

$\mathrm{Na}$ introdução, os autores deixam claro que encontrar explicação, sentido e finalidade para a vida sempre foi uma necessidade humana, ou seja, a questão do ser e do devir toma centro das preocupações, principalmente, científicas e filosóficas. Enquanto Nietzsche aposta numa noção filosófica (artístico-trágica) para a vida humana, Agamben retoma a ideia antropológica de Aristóteles de homem animal político porque animal de linguagem. Contudo, o ponto de contato de Nietzsche e Agamben se mostra na visão da constituição de mundo, pois ambos acreditam nas relações de poder, na vida capturada pela política. Apesar de todas as tentativas de se definir a vida, Assmann e Bazzanella (2013, p. 20) esclarecem:

\footnotetext{
${ }^{1}$ Doutora em Ciências da Linguagem pela Universidade do Sul de Santa Catarina (UNISUL).
} 
qualquer definição conceitual de vida implica na imposição de uma visão reducionista diante da multiplicidade de dimensões e possibilidades contidas nesse fenômeno passageiro, que se manifesta espacialmente e temporalmente em devir, 'entre dois', o ser e o não-ser, a vida e a morte.

\section{A VIDA COMO PONTO DE INFLEXÃO ENTRE O PENSAMENTO DE NIETZSCHE E AGAMBEN}

A primeira interrogação que Assmann e Bazzanella se deparam é como aproximar Nietzsche a Agamben uma vez que estes são pensadores de significativas diferenças conceituais e temporais. Uma maneira de aproximá-los é via reflexões que ambos fazem da condição humana de ser e estar no mundo, que resulta da apropriação da linguagem e da capacidade de significar, de simbolizar, de conceituar, pois "é a partir da condição de animais falantes que se pode pensar o próprio pensamento, o pensamento pensando o pensamento" (Ibidem, p. 35). Contudo, é preciso saber das limitações que a linguagem tem na pretensão de apreender o mundo, de compreender a realidade. Como a vida é o que os homens linguisticamente dizem o que é vida, a linguagem acaba por definir modos de existência ao conceituar a vida, pois estabelece e determina as relações humanas. Assmann e Bazzanella afirmam que "aquilo que se define como vida apresenta-se como forma de vida, como adequamento existencial ao contexto civilizatório em curso" (Ibidem, p. 47). Os autores nos lembram de que, para Freud, a civilização é uma camisa de força que reveste a vida, dando-lhe finalidade e sentido. Essas formas de vida constituídas no processo civilizatório pressupõem sofrimento, porque os modos de civilização estão acompanhados de adestramento dos impulsos vitais humanos, como por exemplo, a necessidade imanente de reinventar a própria existência. Em Nietzsche, temos uma forte crítica ao platonismo instaurado no pensamento ocidental, em que se lê a impossibilidade de conhecermos o mundo pelas sensações e percepções, uma vez que os sentidos são enganadores, mas a filosofia a marteladas de Nietzsche quebra com esse pensamento que defende a razão como a única e verdadeira maneira de entender e construir a realidade. Na modernidade, com a morte de Deus, nascem outros modos de transcendência (Estado, ciência, história, técnica etc.) que pretendem dar sentido à vida, oferecendo guias para os homens agora desamparados pela divindade e desejosos por dar sentido à própria existência. Agamben vê a possibilidade de sairmos do esquema metafísico pela consciência da necessidade de resgatar a experiência da linguagem, que significa ter "experiência com a Voz que funda o ser humano, que procura dizer o ser sem nada dizer, que diz algo sobre o mundo e a vida mantendo-os em sua condição sem conceito, inapreensíveis" (Ibidem, p. 53-54). Dessa maneira, a experiência da linguagem paralisaria o tempo e o progresso, e a nossa posição crítica, criativa e ética desestabilizaria o poder biopolítico disciplinante e normatizador, que massifica as vidas de acordo com a lógica da produção e consumo.

Com a ideia de vida imanente, contingente e infinita Nietzsche também questiona o tempo e põe em jogo as forças que emanam da vontade de poder (da criação e recriação na imanência do devir), mas deixa evidente que as estratégias civilizatórias 
ocidentais tendem a domesticar o homem, a submetê-lo a formas-de-vida e, assim, apequenar sua existência. Nesse ponto, Agamben se apropria do debate nietzschiano sobre as formas-de-vida e percebe que a política na modernidade, ao não mais separar os conceitos aristotélicos de bios e zoé, invade a polis excluindo a vida humana da natureza e das necessidades desta. Por esse viés, Assmann e Bazzanella afirmam que o projeto civilizatório, de acordo com Nietzsche, faz do homem um animal de rebanho para torná-lo obediente aos padrões morais e sociais, reprimindo assim a potência de vida. Nesse sentido, Agamben entende que a política se apodera da vida, dando-se o direito de classificar, desqualificar e sacrificar a vida humana, transformando a vida em vida nua. Aqui a vida é protegida pela lei e, ao mesmo tempo, à margem da lei, que é a lógica dos Estados-nação, em que a condição de produção e consumo precisa dar manutenção ao mercado. Além desses vários pontos de contato, Assmann e Bazzanella (Ibidem, p. 87-88) apontam: "tanto em Nietzsche, quanto em Agamben constatamos esse movimento de tomar a vida como lócus de resistência a esses poderes de apequenamento da vida humana, como por outro lado o lócus da instauração de outras possibilidades e formas vitais". A resistência necessária aos poderes é pontuada por Agamben, que indica a biopolítica como estrutura da política ocidental, cujo poder rebaixa a vida à vida nua, àquela que pode ser descartada na medida que não mais atende aos interesses administrativos e econômicos do Estado.

Há entre a noção de vida de Nietzsche e Agamben uma sutil e importante diferença: enquanto, para Nietzsche, a vida é vontade de poder (potência); para Agamben, a vida é pura potência, potência do pensamento. Nesse ponto, eles se tocam novamente, pois nessa potência ou vontade de potência está o poder de criação, a potência estética de criar e de não-criar, de recriar e de não-recriar. Nietzsche concebe a vida como fenômeno estético, e Agamben como obra de arte, atividade de livre fruição.

Assmann e Bazzanella (Idem) afirmam que a vontade de poder não quer dizer, para Nietzsche, domínio sobre os mais fracos, mas "a possibilidade do ser humano de realizar uma intensa experiência estética com a própria vida”. Já a vida como potência do pensamento é um constante vir-a-ser, é potencialidade e criatividade de si mesma. Além disso, a potência do pensamento poderia ser uma saída para a condição do homem na contemporaneidade, este que se tornou niilista ressentido, visto que vê desmoronar os sonhos civilizatórios que prometiam, através da força legisladora, a vida justa e feliz. Sem mais ilusões, o que sobra é a autoprivatização, os interesses particulares "a partir das pequenas verdades cotidianas e efêmeras da ciência, da técnica, da compulsiva produção e consumo de mercadorias" (Ibidem, p. 54-55).

\section{PARA UMA CRÍTICA DA FILOSOFIA DA HISTÓRIA A PARTIR DE NIETZSCHE E AGAMBEN}

Nossa concepção de história está vinculada aos pressupostos da fé judaico-cristã, no tempo tripartido (passado, presente e futuro), possibilidade de mensurar e controlar o tempo. Para compreender como Nietzsche e Agamben lidam com a história, Assmann e 
Bazzanella buscam como eles lidam com o tempo, visto que sem tempo não há história. É na história que procuramos sentido e finalidade para a vida.

\begin{abstract}
Nietzsche somente concebe uma justificativa à história se esta estiver a serviço da vida, mesmo sendo a vida um evento atemporal, pois seu acontecimento não está vinculado à temporalidade logicamente determinada dos eventos históricos. Estabelecer marcos temporais é uma necessidade humana, e não da vida em sua totalidade. Dessa forma, a história se apresenta como manifestação pontual e contingente da necessidade humana, num tempo de realização vital que se manifesta na intemporalidade não-histórica do mundo (Ibidem, p. 104).
\end{abstract}

Os gregos não interrogavam o senhor da história, mas o logos do cosmos, uma vez que se ocupavam em saber o porquê do sofrimento e da morte. Já a modernidade procura pelo sentido da vida, desnaturalizando e desdivinizando

\footnotetext{
o cosmo, o mundo, a dinâmica vital e assumiu como tarefa encontrar um fundamento lógico, racional e científico que lhe conferisse garantias, certezas e segurança diante da realidade necessária e contingencial na qual se encontrava inserida (Ibidem, p. 106).
}

Para Agamben, é na modernidade que nasce a necessidade de dar finalidade e sentido à existência, consequência da cisão entre humano e animal provocada pela linguagem, em que a potência humana pode ser experimentada. É na linguagem que o eterno pode ser contingente e o tempo ser passageiro.

A anunciação da morte de Deus, por Nietzsche, é lida por Agamben como necessidade de profanação da vida, ou seja, "devolver ao uso comum aquilo que foi sacralizado, retirado da comunidade dos seres humanos", de acordo com Assmann e Bazzanella (Ibidem, p. 113). Esse retorno ao mundo dessacralizado significa também uma nova experiência com o tempo, que pode, como sugere Agamben, promover uma crítica do instante numa perspectiva messiânica, de Walter Benjamin: vivenciar o tempo que resta, pois a vida é o que existe neste instante imanente. Esse tempo tripartido foi o que fez com que deixássemos de vivenciar experiências vitais, pois a perda da noção de tempo gera uma rotina diária de massificação da produção e do consumo, deixando a vida para uma dimensão futura e a crença no progresso. Essa racionalidade administrativa da vida, desde a modernidade, é geradora de vida nua. Dessa maneira, Assmann e Bazzanella entendem que, já que toda concepção de história necessariamente dita um modo de experiência do tempo, a revolução, segundo Agamben, não seria mudar o mundo, mas sim a nossa relação com o tempo, pois o tempo que resta "é o único tempo real, o único tempo que temos, e fazer a experiência desse tempo implica em transformação integral de nós mesmos e do nosso modo de viver" (Ibidem, p. 148). O tempo que resta não significa, portanto, a aposta na salvação futura, uma vez que é presentidade e facticidade diárias em cada instante. Para Assmann e Bazzanella, o tempo que resta é a condição da experiência aqui e agora com a vida, é o tempo de dizer não. 


\section{AS FORMAS DE VIDA NA CONTEMPORANEIDADE A PARTIR DA GRANDE POLÍTICA EM NIETZSCHE E DA POLÍTICA QUE VEM EM AGAMBEN}

Para compreender a política em Nietzsche e Agamben, Assmann e Bazzanella vão em Bauman, que aponta a civilização moderna como a que tornou possível o Holocausto. Nela ainda nasce o niilismo, o fim das utopias juntamente com a morte do sujeito histórico, do sujeito da experiência. Nesse tempo de produção e consumo, os sujeitos são retirados do âmbito público, das decisões políticas e colocados a serviço da administração jurídica, esta que, regida por interesses econômicos, faz viver ou deixa morrer em nome da legalidade política.

Como saída para esse esquema, Agamben sugere deixarmos de lado as maneiras cristalizadas de pensamento, questionando, mobilizando, potencializando o pensamento - essa é a política que vem, a política que é a manifestação da experiência do pensamento, que é potencialidade de vida, de ser e de não ser. A grande política de Nietzsche aponta para o abandono de valores secularizados e para a potência de experiências, pois é no jogo de forças que a vida se renova. Essa grande política traz uma visão apolínea e dionisíaca de mundo; imbricadas, ambas as forças potencializam a vida, uma vez que, enquanto a função de Apolo é dar forma e harmonizar o cosmo, Dionísio viola o princípio individual e invoca a desestabilização através da vontade de viver, do êxtase, provocando, na deformidade, um estar fora de si. Com essa dupla, Nietzsche propõe reinventar a vida a todo instante, fazendo da vida uma obra de arte.

A partir da grande política e da política que vem, Assmann e Bazzanella nos dão a chave para compreendermos que a vida na modernidade, uma vida regida pela biopolítica (controle que o Estado faz sobre a vida) e pela tanatopolítica (controle que o Estado faz sobre a morte), pode ser redefinida sem as amarras do pensamento estatal, religioso, econômico e científico. Assim como Agamben vê o Estado como controlador de formas de vida, Nietzsche o entende como um monstro (bando de bestas louras), que transforma os humanos em rebanho para que possa ordenar, regular e extirpar a particularidade de cada humano, de cada força. Isso não que dizer que Nietzsche apoie o anarquismo e o fim do Estado, o que ele defende é a justiça e o partido da vida.

A política que vem, de Agamben, apoiado em Nietzsche, é uma maneira de criticar a modernidade, a máquina antropológica que, ao mesmo tempo em que nos constitui como humanos, provê a biopolítica e justifica a tanatopolítica. Assmann e Bazzanella entendem que Agamben traz uma visão pessimista da política ocidental, mas também veem a possibilidade de a política que vem ser uma maneira de enfrentar os controles impostos pela soberania das instituições através da manifestação da experiência do pensamento. Esse poder soberano é que deixa a vida exposta aos campos de concentração. Em nome do direito, a biopolítica se apodera das vidas e as transformam em vida nua.

Nessa leitura de Nietzsche a Agamben, Assmann e Bazzanella (2013, p. 185) constatam que 
nesses pressupostos biopolíticos da contemporaneidade convive-se com a constante e crescente necessidade de se redefinir a vida. Situada numa zona de indecidibilidade, a vida é requisitada em sua polissemia para as mais variadas finalidades. Apreendida por dispositivos científicos e técnicos, mas especificamente no campo da medicina, requer-se cada vez com maior intensidade que se estabeleça pressupostos que amparem questões da seguinte ordem: O que significa vida? Em que momento inicia a vida biológica? O que é a morte? Quando se pode afirmar que alguém está morto?

Essas questões estão na base da política contemporânea, em que o aspecto biológico da vida humana define os imperativos biopolíticos, os poderes jurídicos que agem com a violência legitimada e soberana do Estado. É esse poder ordenador e qualificador que torna o homem um consumidor de produtos e serviços que prometem não a vida eterna, mas a saúde e a longevidade. Enquanto a fé nos especialistas e no poder do Estado se mantiverem, haverá espaço para a pequena política, a biopolítica e a tanatopolítica. A política que vem e a grande política são as possibilidades de força e resistência contra o controle das formas de vida e a condição meramente biológica do humano. Em contrapartida, é essa promessa por saúde, segurança e bem estar financeiro que apreende os sujeitos, tornando-os massas administráveis contemporâneas. É ainda a política que vem, de Agamben, e a grande política, de Nietzsche, que nos fazem exigir a vida no centro dos debates contemporâneos.

Uma última aproximação entre Nietzsche a Agamben feita por Assmann e Bazzanella é quanto à concepção de vida como obra de arte por um cunho trágico e profano. A vida definida por Nietzsche coloca o homem além do próprio homem, um humano capaz de resistir aos valores institucionalizados e, assim, participar ativamente da experiência trágica da vida, que é o que Agamben também aponta para a possibilidade de experienciar a vida como obra de arte. Nas palavras de Assmann e Bazzanella:

viver a vida na precariedade imanente e contingente do mundo exige dos seres humanos conceberem a vida como arte, como impulso criador e contínuo movimento em direção à experiência com o mundo em suas potencialidades vitais, com outros seres humanos que vivem e convivem nesse mundo no tempo presente (Ibidem, p. 190-191).

Em Nietzsche, essa analogia com a arte compreende viver com a perspectiva do artista trágico, espírito crítico e livre que observa a vida e participa da constituição do mundo. A vida para Nietzsche é vontade de poder. Em Agamben, a arte abre possibilidades outras de pensar a vida, de viver outras formas de vida nesse tempo que nos resta. A vida para Agamben é potência do pensamento.

Recebido em: 15/06/2014. Aprovado em 15/06/2014. 